\title{
Fundamental Research Problems of Vocational Education (Based on Research of the Institute of Pedagogy and Psychology of Vocational Education RAE for 2013)
}

\author{
Farida Shamilevna Mukhametzyanova ${ }^{1} \&$ Gasanguseyn Ibrahimovich Ibragimov ${ }^{1}$ \\ ${ }^{1}$ Institute of Pedagogy and Psychology of Vocational Education RAF, Russian Federation \\ Correspondence: Farida Shamilevna Mukhametzyanova, Isaeva Street, 12, Kazan, 420039, Russian Federation.
}

Received: December 9, 2014 Accepted: December 29, $2014 \quad$ Online Published: March 20, 2015

doi:10.5539/ass.v11n8p149 URL: http://dx.doi.org/10.5539/ass.v11n8p149

\begin{abstract}
The article describes the main directions (theoretical and methodological grounds and innovative models of vocational education and retraining in a changing labour market; theory and practice of specialists training under conditions of scientific and educational clusters in different fields; didactic and methodological provision of vocational education content, project and target-oriented mechanisms for implementation of the federal state educational standards of secondary vocational education; meta-dynamic grounds of productive functioning of vocational school informational and educational environment ) and the results of fundamental research of the Institute in the field of scientific support for vocational education, obtained in 2013.
\end{abstract}

Keywords: vocational education, fundamental research in the field of vocational education, modernization of vocational education

\section{Introduction}

Education is a socio-cultural phenomenon which is of priority both for an individual and for preservation and development of the society. In this context, modernization of the Institute of Vocational Education, within which training of workers and specialists of different levels and profiles is implemented, serves as one of the main objectives of the educational policy of the state. This is why research activity of the Institute of Pedagogy and Psychology of the Russian Academy of Education is aimed at analysing the status and prospects of development of fundamental science in the field of vocational education on the subject of ongoing research and is connected with current issues, which characterize possible ways of developing and improving professional training of future workers and specialists of secondary and higher qualification. When solving these problems, we rely on studies of real processes occurring in the system of vocational education. A cross-cutting idea of the Institute research is the idea of integration of education, science and industry.

The Institute conducts research on the subject, forming a part of five projects ("Theoretical and methodological grounds and innovative models of vocational education and retraining of specialists in a changing labour market", "Theory and practice of specialists training under conditions of scientific and educational clusters in different fields," "Multicultural grounds and didactic support of vocational education content", "Project and target-oriented mechanisms of implementing the federal state educational standards of primary and secondary vocational education", "Philosophical and methodological, medico-psychological, social and pedagogical grounds for creating and developing informational and educational space") of the plan of fundamental and applied research of the RAE. At the same time the cross-cutting idea of the Institute research is devoted to integration of education, science and industry. We will briefly reveal the main results that we obtained in 2013 .

\section{Methodological Grounds and Innovative Models of Specialists Training}

Under present conditions of socio-economic development of the country, characterized by a high degree of uncertainty in all spheres of human activity, there is an urgent need to create a conceptual and methodological foundation of education systems research based on the synthesis of concepts of pedagogical science with achievements of philosophical hermeneutics, existential philosophy and psychology. Studies have shown that while creating self-organizing systems of education, it is necessary to use multivariate models based on new concepts. They are based on: the principle of proliferation, consisting in growth of innovations in science and education on the basis of multiplication of competing theories; the principle of balancing needs of individuals, 
social groups and a state, providing best interests of presented subjects of education; the principle of subsidiarity, based on the fact that people can show themselves in two planes at a time: as an autonomous person and as a medium of social relations; the principle of adequacy, establishing interconnectivity of political, economic and cultural environment with functional-structural content of education; the principle of complexity (the law of necessary variety) provides formation of different personality types for needs of reproduction of culture and civilization through educational tools, based on philosophical theory of understanding - hermeneutics; the principle of self-similarity, which forms fractal development of management and self-management of educational systems; the situational principle, which determines a development vector of an educational system in the information society, taking into account a variety of contexts and events during a certain period.

Manufacturing and service sector require workers, who are enterprising, initiative and are focused on search of new approaches aimed at solving emerging problems. At the same time, studies have shown (students, majoring in "Water Supply and Sanitation", of the Kazan State Architectural University have been interviewed) that $32.2 \%$ of students rated their willingness for entrepreneurial activity as low, $57.3 \%$ - as average, $0.0 \%$ - as high This poses the problem of using new training models for workers and specialists to the system of vocational education. As a result of the studies, the technology of designing modules of innovative entrepreneurship training, was elaborated, it includes the following steps: preparatory, specification of innovations; module specification; substantive content of the module (requires design of a structure and content of the interdisciplinary course "Innovative entrepreneurship".

With the development of science-intensive industries, increasing automation and intellectualization of labour and services sectors, the role and importance of such competence increases as readiness for self-employment. The study showed that only $3 \%$ of students are ready for possible careers in self-employment. At the same time, about $60 \%$ of students show high interest in the examined form of activity. Taking this into account, we developed the model of training future professionals for self-employment, in which elements and connections enable integration of the content and development forms of students' strategic initiatives (preparation and implementation of innovative projects) in the structure of vocational education curricula. Technologies of training future professionals for self-employment envisage practical professional training for students through contractual arrangements, internship, participation in innovative projects, scientific conferences, preparation of thesis projects, reports, speeches and dissertations at various stages and levels of education.

\section{Psycho-pedagogical Grounds for Preparation of Teachers of Vocational Schools}

Preparation of competent workers and mid-level professionals in educational institutions of secondary vocational education presupposes availability of appropriate staff - teachers and vocational trainers. In this context, four organizational and pedagogical conditions that improve effectiveness of training of teachers of vocational education were identified and justified. The first condition - involvement of social partners in the educational process as an effective mechanism for professional and personal development of a specialist, aimed at bilateral mutually beneficial cooperation, which allows building a relationship of trust and exchange of information, related to analysis of needs of today's market, a study of employers' requirements to specialists. The results of the analysis give an idea of what kind of a graduate will be in demand in a regional labour market, what professional competencies he/she should have, and adjust the content of training on this basis. Therefore, the model of a specialist is designed, since it is in constant motion due to changing requirements of employers and production; a practical part of the training is constructed to meet requirements of modern production and requirements for teachers of vocational education; content of special and practical training is adjusted.

The second condition is early formation of a professional appearance, due to a necessity of formation of motivation among students for future careers. A positive attitude towards a chosen profession, understanding of the essence and its social significance comes not only at classes of a professional module, pedagogical and practical training, but also at classes of humanities, when all the environment of an educational institution is permeated with the spirit of a future profession. It is necessary to develop general humanities modules of educational programmes so that they are aimed at forming motivation and sustained interest to a profession of a master/teacher of vocational education, motivation of self-understanding, personal growth and self-improvement. Given the integrative capabilities of FSES, we offer to allocate a module, aimed at vocational guidance for future teachers of vocational education in curriculum for each discipline, or an integrative interdisciplinary module within a diversity potential of the standard. Implementation of this module should be implemented from the first year of study. Knowledge of major trends in education, main stages of pedagogy and schools formation, personal contribution of domestic educators-innovators in development of pedagogy and education, formation and development of the profession of a teacher of vocational education contribute to early professionalization of a future specialist. 
The third condition is organization of prolonged academic and practical training of students, i.e. ensuring continued inclusion of students in education and production process by participating in competitions of professional skill, contests, meetings with production workers, activities of professional clubs, participation in professional exhibitions, etc. Inclusion of this provision in the educational process of preparation of a teacher of vocational education is dictated by a need to preserve and develop interest of students for their future profession, narrowing a gap between kinds and types, terms of practice, because practice is the only type of training, which is maximally similar to the profession.

The fourth condition is readiness assessment (theoretical and practical) of students for future careers at all stages of education in relation to the competence-based approach.

To draw a structure of training nearer to real needs of the labour market, various models of integration of vocational education, science and industry are implemented. For example, in the Republic of Tatarstan it is a cluster model that combines educational and other organizations and institutions of different levels, types and kinds. Training technologies of students in the educational cluster have their own characteristics, because they are designed to meet requirements of sectoral production and educational standards at various levels: organization and structure; content; methods.

As part of psychological support of vocational education, the main theoretical approaches to the problem of professional and personal development of a future professional as a subject of life activity, i.e. a person capable of consciously implementing different ways of organizing his/her activity for optimal implementation of life-purpose relations to the outside world, are identified. The criteria for a future specialist being a "subject of educational activities" and a "subject of life" are determined, among which a priority for further in-depth studies is a development level of effective self-reliance and adaptability of a "rising balance".

\section{Didactic Maintenance of Vocational Education Content}

In the context of modernization of vocational education, problems of didactic support of vocational education content become quite urgent. Essential characteristics of education in a vocational school under conditions of informatization of education were identified: a growing role and place of a teacher's constructive function; increase in kinds of independent educational and professional activities, implemented on the basis of information and computer technologies; transformation of the basic didactic content into the triad "learning activity information, professional and educational environment - pedagogical activity", emergence of new forms of structuring learning content (hypertext and hypermedia), which ensure its selection in accordance with personal preferences of a student; increase in kinds of teaching materials (electronic textbooks, electronic tests, instrument modelling tools of training material, training and monitoring software and so on.), which perform not only a function of a new tool in a modern learning, but also a didactic condition, conducive to students' key competencies, allowing them work in information-educational environment. Problems of a learning process in a higher school at the project level (for example, a Bachelor in "Teacher Education") are determined: reduction in the proportion of humanities and socio-economic and science disciplines, responsible for fundamentalization of vocational education; undeveloped didactic means of providing an organic interrelation of disciplines results with mastered knowledge, skills and acquired competencies as a whole on the basic educational programme for bachelors; incomplete compliance of the existing training and methodological support (textbooks and manuals) with standards of the third generation; discrepancy of principles of formation and content of assessment tools with FSES requirements to results and others.

In the process of studying the problem of designing and implementing the content of the sciences and the general professional training in secondary vocational school under conditions of FSES implementation, it is identified that current requirements for updating training courses require mandatory use of competence-based and modular approaches in their design. However, the content and structure of textbooks do not take into account the FSES SVE requirements, because they basically repeat the previous textbooks and are rewritten in a more complicated version ("pseudo-scientific"). A need to self-design the entire course both as a whole and as individual lessons is recognized by most teachers. However, they encounter difficulties: in designing the learning environment in accordance with emergence of new knowledge and technologies; in designing and defining a purpose of training related to formation of competencies; in determining a structure of lessons, in selecting and structuring professional and meaningful material, which allows quickly updating content of training and organization of educational activities of students. 


\section{Project and Target-oriented Mechanisms of FSES Implementation of Secondary Vocational Education}

An important area of research of the Institute is development of project and target-oriented mechanisms of implementation of the federal state educational standards of secondary vocational education. It was found that the independent PVE (primary vocational education) system is de facto eliminated and is converted into the initial stage of the SVE (secondary vocational education) in terms of content. So, in Chuvashia a number of students enrolled in programs of PVE fell by half (compared to 2000), a number of graduates (skilled workers) is reduced, who are assigned to production facilities by an establishment of primary vocational education (in 2000 7982 people, 2012 - 3582 people). Main risks of FSES implementation of secondary vocational education were identified: inadequate methodological support of a quality assessment system of professional competence; inadequate legal and regulatory framework, governing relationship of educational institutions with enterprises customers requiring workers; mismatch of material-technical base of an institution with new requirements. A multicomponent algorithm of project and target-oriented mechanisms of FSES implementation of humanitarian preparation of students is designed. It includes: a design phase, technological phase and a reflective phase. Criteria for their selection are defined: social significance, ability of subjects of designing activity to continuous operation, development and self-development, completeness of a design intent implementation, a degree of mastering design procedures, appropriate context design, satisfaction with participation in a project, correspondence to a cultural analogue, a need for further development of project experience. In the context of the design paradigm, scientists of the Institute elaborate a project and development-oriented approach to the educational process in institutions of secondary vocational education. It is considered as a way of achieving an educational goal through detailed development of a pedagogical event, life and professional situations, inclusion of educational problems into the context of life problems, identifying a priority of personality-sense responsibility, aimed at development, establishment and formation of a student's personality, his/her physical, mental and social health, which should be completed with a projected practical result. Three groups of principles of implementing the project and development-oriented approach: a subject of subject interaction and cooperation in the educational process; personal-semantic organization of project activities; training teachers to implement the project and development-oriented approach to the educational process in the vocational education system.

\section{Meta-dynamic Grounds for Productive Functioning of the Informational and Educational Environment of a Vocational School}

Within the framework of the research of pedagogical grounds for creating and developing informational and educational space, a meta-dynamic specificity of functioning of the informational and educational environment of a vocational school is covered. From a position of providing productive training of specialists under conditions of the informational and educational environment of a university, significant aspects of improving its components were identified: essential differences of dynamic characteristics of search and research students' activities, obtaining education of different levels and profiles; functioning of individual information environments of interacting subjects of the educational process at the levels of pre-vocational and vocational training, and others. Studies have shown a consistent dependence of conservation of information and research activities from the systemic organization of joint scientific work of teachers and students. The most positive attitude towards the use of innovative information resources is noted in teachers (42-58\%) and junior students $(30-45 \%)$. Senior students' aspire mostly to existing resources in the professional activity and only $10-20 \%$ of the students retain their interest to innovations.

\section{Foreign Experience of Competence Formation in the System of Additional Vocational Training}

In the European practice of vocational education, according to results of the Institute research, there are four models of competence, which have different approaches to organization and evaluation of students' achievements. The first model is based on development of a person's already existing human abilities (moral, spiritual, personal qualities) in the educational process; the second model is prevalent in preparation of technical specialists and in their "fine-tuning" at a workplace through algorithmic procedures; the third model of competencies places such learning environment, in which a certain motivation and ability to design, evaluate and analyse various plans and strategies is formed; the fourth model of competencies is focused on needs of employers and the social context of possible jobs. Together the results, obtained in the course of research, expand scientific understanding of ways of solving the problem of competencies formation in the system of additional vocational education, developed in domestic and foreign pedagogical science, in order to improve competitiveness of professionals working at global and regional labour markets. 


\section{Conclusion}

The results of fundamental and applied research of the Institute are widely known through the use of various forms of their implementation in practice of vocational education. Application areas of research results are not only vocational education institutions at various levels, but also management bodies of professional education at the federal and regional levels, the system of additional vocational education, employment services, and others. Prospects for further development of fundamental research in the field of vocational education are related to elaboration of methodology and theory of its new role in the innovative economy.

\section{References}

Chitalin, N., \& Mutigullina, A. (2013). Competence-based approach in designing and implementing the general professional discipline "Anatomy and physiology of a person" (from experience of the medical college). In N. A. Chitalin, \& A. R. Kamaleeva (Eds.), Experience in designing science and general professional training courses under conditions of FSES SVE implementation: A collection of scientific articles. Kazan: Publishing house "Danis".

Coles, M., \& Werquin, P. (2008). The role of national qualifications systems in helping to modernize vocational education and training systems. In B. Cedefop (Ed.), Modernising vocational education and training Fourth report on vocational education and training research in Europe: background report Volume 3. Luxembourg: Office for Official Publications of the European Communities, (Cedefop Reference series).

Education and Training 2020. (n. d.). Retrieved December 19, 2014, from http://europe.eu/legislation

Gilmeeva, R., Mukhametzyanova, F., Tikhonova, L., Muhametzyanova, L., \& Shaikhutdinova, G. (2013). Formation of the common culture and education in humanities of vocational school students: Aspect of the scientific and methodological support. Electronic interdisciplinary journal (Middle East Journal of Scientific Research), 15(7), 931-936.

Ibragimov, G. (2013a). Didactics of a vocational school: Collection of scientific articles. Kazan: IPPVE RAE.

Ibragimov, G. (2013b). The process of learning in higher education under conditions of FSES implementation: pressure points. Alma-mater (Bulletin of the higher school), 8, 6-14.

Ibragimov, G., \& Ibragimova, E. (2013). Nature and guiding principles of concentrated training. Innovations in education, 5, 14-25.

Kamaleeva, A., Galimov, N., \& Chitalin, N. (2013). Technology for elaborating variable programmes of science and mathematics and general professional disciplines taking into account requirements of the third generation standards and areas of training (for teachers of technical universities): Methodological textbook. Kazan: Publishing house "Danis".

Kirilova, G., \& Vlasova, V. (2013). The integration potential of the informational and environmental approach in vocational education. Philology and Culture, 1(31), 244-251.

Kolpakova, L. (2013). Features of behavioural components of college students' consciousness in different types of readiness to changes. Kazan pedagogical journal, 3(98), 133-142.

Maslennikova, V. (2013). Project and development-oriented approach aimed at promoting healthy lifestyle in institutions of vocational educational organizations. Bulletin of the Kazan State University of Culture and Arts, 3, 12-19.

Muhametzyanova, F., \& Shaikhutdinova, G. (2012). Innovative principles in preparation of teachers of vocational training. Kazan pedagogical journal, 1, 25-35.

Nordkvelle, Y. (2003). Didactics: From classical rhetoric to kitchen-Latin. Pedagogy, Culture \& Society, 3(11), 315-330. http://dx.doi.org/10.1080/14681360300200177

Nurullin, R. (2013). Vocational education as a system in the context of modern processes of integration. Scientific notes of the Kazan Federal University, Kazan, KFU, 1(155), 137-146.

Owens, G. (2002). The Module in "Universities Quarterly". Universities Quartely, Higher education and society, 1(25), 20-27.

Ruthven, K. (2012). The didactical tetrahedron as a heuristic for analyzing the incorporation of digital technologies into classroom practice in support of investigative approaches to teaching mathematics. 
ZDM, 44(5), 627-640. http://dx.doi.org/10.1007/s11858-011-0376-8

Safin, R., \& Zyalaeva, R. (2013). Design of training modules for innovative entrepreneurship in a vocational school. Kazan: IPPVE RAE.

Safin, R., Matuhin, E., Shaydullina, A., \& Zyalaeva, R. (2013). Formation and development of innovative entrepreneurship education in secondary and higher vocational schools in Russia. Scientific and methodical textbook. Science editor G. I. Ibragimov. Kazan: Publishing house "Danis".

Scherbakov, V. (2011). Integration processes in the structure of modern educational trends. In G. V. Muhametzyanova (Ed.), Aspects of integration processes in vocational education: A collection of scientific articles. Kazan: IPPVE RAE.

Schoenfeld, A. (2012). Problematizing the didactical triangle. ZDM, 44(5), 587-599. http://dx.doi.org/10.1007/s 11858-012-0395-0

Tregubova, T. (2013). Comparative studies on vocational education: Major trends and problems of adaptation. Kazan pedagogical journal, 3, 33-39.

\section{Copyrights}

Copyright for this article is retained by the author(s), with first publication rights granted to the journal.

This is an open-access article distributed under the terms and conditions of the Creative Commons Attribution license (http://creativecommons.org/licenses/by/3.0/). 